\title{
POLA PENGGUNAAN DAN KERASIONALAN OBAT TERHADAP LAMA RAWATAN PADA PASIEN MALARIA DI RSUD Dr. M. YUNUS BENGKULU
}

\author{
Riana Versita ${ }^{1)}$, Dedy Almasdy ${ }^{2)}$, dan Zaini Dahlan ${ }^{3)}$ \\ ${ }^{1}$ D3 Farmasi FMIPA Universitas Bengkulu \\ ${ }^{2}$ Fakultas Farmasi, Universitas Andalas, Padang, Sumatera Barat \\ ${ }^{3}$ Rumah Sakit Umum Daerah Dr. M. Yunus Bengkulu \\ E-mail: riana.versita@unib.ac.id
}

\begin{abstract}
Problems: Inappropriate use of antimalarials results in not achieving therapeutic goals, and the occurrence of resistance to antimalarials. The Aim of The Research: This study was aimed to describe the relationship of drug uses rasionality, disease severity and pattern of drug uses on Malaria at Dr. M. Yunus Bengkulu Hospital. Research Method: This was in observasional study with crosssectional using datas of medical record with 78 respondens. The Results: Relation of sociodemographic characteristic in group of age was 4.314 times impacted than gender and education on changing diagnosis. Where moderate severity has longer duration of treatment than mild severity, while in cost of treatment was not significantly ( $p>0.05$ ). In pattern of drug, single and combination was not significantly ( $>0.05)$ on duration of treatment, in statistically, single drug uses was more effective but should be researched about relapse incidence on malaria patient which use single drug. Conclusions: Rationality of drug relations against duration of treatment was significantly $(\mathrm{p}<0.05)$, rational drug has shorter duration than irrational drug of treatment, so more effective and efficient. This study also showed DRP with improper drug selection was $34.26 \%$.
\end{abstract}

Keywords: Malaria, Bengkulu Hospital, Drug Evaluation

\begin{abstract}
ABSTRAK
Permasalahan: Penggunaan antimalaria secara tidak tepat mengakibatkan tujuan terapi tidak tercapai, dan terjadinya resistensi terhadap antimalaria. Tujuan Penelitian: Penelitian ini bertujuan untuk mempelajari kerasionalan penggunaan obat dan pola penggunaan pada pasien malaria di RSUD Dr. M. Yunus Bengkulu. Metode Penelitian: Penelitian ini adalah observasional dengan pendekatan Cross-Sectional menggunakan data rekam medik. Sampel penelitian berjumlah 78 responden. Hasil: Hasil penelitian menunjukan hubungan karakteristik sosial demografi terhadap perubahan diagnosa, kelompok usia lebih berisiko dan berpengaruh 4,314 kali terhadap terjadinya perubahan diagnosa dibandingkan jenis kelamin dan pendidikan. Pada pola penggunaan obat terhadap lama rawatan diperoleh obat tunggal dan kombinasi tidak berbeda secara bermakna terhadap lama rawatan $(p>0,05)$ secara statistik penggunaan obat tunggal lebih efektif tetapi perlu dilakukan penelitian lebih lanjut tentang kejadian relaps pada pasien malaria yang menggunakan obat tunggal. Kesimpulan: Hubungan kerasionalan obat terhadap lama rawatan perawatan berbeda secara bermakna $(\mathrm{p}<0.05)$, obat yang rasional mempunyai lama rawatan yang lebih singkat dibandingkan dengan obat tidak rasional, sehingga lebih efektif dan lebih efisien dapat menghemat anggaran belanja obat jika digunakan obat secara rasional. Hasil pengkajian antimalaria yang sudah tepat atau sesuai $(34,26 \%)$.
\end{abstract}

Kata kunci: Malaria,RSUD Dr.M.Yunus Bengkulu, Evaluasi Obat 


\section{PENDAHULUAN}

Malaria merupakan salah satu penyakit menular yang menjadi masalah kesehatan masyarakat di dunia termasuk Afrika, India, Ganna, Nigeria dan Indonesia (WHO, 2013; Chedi, et al., 2010; Mubeen, et al., 2012). Setiap tahun lebih dari 500 juta penduduk dunia terinfeksi malaria dan lebih dari 1 juta orang meninggal dunia (WHO, 2013; Igboeli, et al., 2010). Di India tahun 2011 terdapat 474 pasien malaria (Mubeen, et al., 2012), di Ganna benua Afrika tahun 2009 sebanyak 4.526 orang terinfeksi malaria (Dodoo, et al., 2009) dan di Gujarat, India tahun 2011 kematian akibat malaria sebesar 30\%. Sedangkan Indonesia, pada tahun 2013 terdapat 396 Kabupaten endemis dari 495 Kabupaten yang ada, dengan perkiraan sekitar $45 \%$ penduduk berdomisili di daerah yang berisiko tertular malaria (Kepmenkes, 2013). Jumlah kasus pada tahun 2012 sebanyak 417.819 dan tahun 2013 sebanyak 343.527 orang (Kepmenkes, 2013).

Faktor-faktor infeksi malaria yang mempengaruhi di masyarakat merupakan interaksi dinamis antara faktor host (manusia dan nyamuk), agent (parasit) dan envirotment (Azwar, 1981; WHO, 1997). Faktor resiko yang diduga berperan terjadi infeksi malaria adalah faktor karakteristik demografi yaitu usia, jenis kelamin, genetik, kehamilan, status gizi, aktivitas keluar rumah (pekerjaan) dan pendidikan (WHO, 2012; Sutisna, 2004). Untuk mengatasi permasalahan penyakit malaria di wilayah endemis perlu dilakukan dengan pendekatan epidemiologis yang mencakup kondisi lingkungan dan sosial ekonomi penduduk (WHO, 2006; Ernawati, et al., 2011).

Meningkatnya penularannya malaria melalui gigitan nyamuk Anopheles betina disebabkan faktor kesehatan lingkungan fisik, kimia, biologis, dan sosial budaya yang sangat berpengaruh terhadap penyebaran penyakit malaria di Indonesia (WHO, 2012; Ernawati, et al., 2011; Anies, 2005).Cara mengatasi permasalahan melalui upaya-upaya kesehatan yang diarahkan dengan pendekatan seperti pemeliharaan kesehatan (promotif), pencegahan penyakit (preventif), penyembuhan penyakit (kuratif) dan pemulihan kesehatan (rehabilitative) yang dilakukan secara menyeluruh terpadu dan berkesinambungan (UU kesehatan, 1992). 
Upaya perbaikan kesehatan masyarakat terus ditingkatkan, antara lain melalui pencegahan dan pemberantasan penyakit menular yang bertujuan menurunkan angka kesakitan dan kematian serta mencegah akibat buruk lebih lanjut sehingga tidak lagi menjadi masalah kesehatan masyarakat, yaitu dengan diagnosis dini, pengobatan cepat, tepat, efektif, efisien, surveilens dengan penggunaan obat yang tepat jenis, dosis, rute, durasi dan frekuensi pemberian obat serta pengendalian vektor yang kesemuanya ditunjukan untuk memutus rantai penularan malaria (WHO, 1995; Depkes, 2009).

Penelitian Evaluasi Penggunaan Obat pada pasien malaria yang telah dilakukan di beberapa negara, hasilnya membuktikan penanganan penderita malaria masi kurang tepat di India yaitu penggunaan obat banyak yang tidak tepat pasien 16,04\%, ketidaktepatan pemilihan obat 41,59\%, ketidakpatuhan meminum obat 80\% (Mubeen, et al., 2012), di Afrika ditemukan ketidakefektifan, dan tidak efisien pemilihan obat 14,3\% (Mosanya, 2001), di Nigeria ditemukan ketidakrasionalan penggunaan obat injeksi 19-28\%, ketidakrasionalan penggunaan Chloroquin 55,5\%, dan ketidaktepatan peresepan obat antimalaria 26,1\% (Mubeen, et al., 2012) serta ketidaktepatan dalam pola penggunaan obat sebesar 41,59\% (Mubeen, et al., 2012) yang mengakibatkan terjadinya kegagalan terapi dan resistensi antimalaria serta meningkatnya angka kematian pasien malaria 30\% dan kejadian relaps 70\% (Limbachia, et al., 2012; WHO, 2012) .

Di Bengkulu sendiri juga sudah banyak dilakukan penelitian tentang malaria dikarenakan propinsi Bengkulu merupakan daerah endemis dimana dari data Annual Malaria Incidence (AMI) Propinsi Bengkulu tahun 2011 sebesar 27,8 per 1000 penduduk, atau sebanyak 37.618 orang yang terinfeksi malaria, Di tahun 2012 tercatat ada 10.134 kasus malaria di Provinsi Bengkulu. Di susul tahun 2013 sebanyak 7.172 kasus, dan di tahun 2014 berjumlah 4.666 kasus malaria. Terakhir dengan indeks penilaian Annual Paracite Incidence (API) Provinsi Bengkulu di tahun 2013 berada di angka 4,06 dan 2014 di angka 2,14. Sementara syarat Millenium Development Goals (MDGs) harus di bawah angka 1(Dinkes, 2011; WHO, 2012).

Prinsip dalam penggunaan antimalaria diperlukan pemilihan antimalaria yang tepat jenis, dosis, rute pemberiannya, frekuensi dan durasi serta pemantauan efikasi penggunaan 
obat (Mubeen, et al., 2012). Kegagalan terapi dengan antimalaria disebabkan oleh tiga faktor yaitu faktor obat, pasien dan parasit. Faktor obat termasuk jenis, dosis, rute pemberian, frekuensi dan durasi pemberian (Wells, et al., 2009).

Evaluasi perlu dilakukan untuk pemilihan antimalaria dan mengatasi masalah yang telah terjadi (ketidaktepatan dalam pemilihan jenis obat, dosis, durasi, frekuensi, rute pemberian) dan mencegah timbulnya masalah baru terkait penggunaan obat (resitensi). Evaluasi tetap perlu dilakukan meskipun telah ada pedoman penggunaan antimalaria disetiap rumah sakit. Hal ini dikarenakan banyaknya ditemukan penggunaan antimalaria tanpa mengikuti pedoman terapi atau tidak memiliki pedoman yang jelas serta banyaknya kegagalan terapi malaria dan terjadi relaps di daerah endemik termasuk Bengkulu.

Akan tetapi belum ada penelitian tentang Evaluasi Penggunaan Obat (EPO). Penggunaan antimalaria secara tidak tepat mengakibatkan tujuan terapi tidak tercapai, dan terjadinya resistensi terhadap antimalaria. Akibat dari resistensi ini, dibutuhkan antimalaria baru untuk mengatasi infeksi yang lama. Namun, proses yang dilakukan untuk menemukan antimalaria baru dan melanjutkan terapi yang efektif membutuhkan waktu yang lama dan biaya yang besar (Permenkes, 2011). Berdasarkan hal ini maka dilakukan penelitian Pola Penggunaan dan Kerasionalan Obat Terhadap Lama Rawatan Pasien Malaria Di RSUD Dr. M. Yunus Bengkulu.

\section{METODA PENELITIAN}

Penelitian ini dilakukan secara observasional dengan pendekatan Cross-Sectional menggunakan data rekam medik yang di evaluasi secara retrospektif dengan metoda consecutive sampling dengan kriteria inklusi 1) Rekam Medik pasien dengan usia 18-65 tahun (dewasa). 2) Positif malaria. Data statistik deskriptif digunakan untuk mendeskripsikan sosiodemografi (jenis kelamin, umur, pendidikan, pekerjaan dan diagnosa) dan hubungan pola penggunaan obat, kerasionalan obat terhadap lama rawatan. Analisis data diambil secara deskriptif analisis secara kuantitatif, dan kualitatif. Analisa kuantitatif dilakukan dengan menguraikan data-data yang didapatkan dari catatan medik: Penyajian data penelitian secara kuantitatif dalam bentuk tabel diagram. Sedangkan analisa 
kualitatif penggunaan antimalaria adalah untuk melihat ketepatan penggunaan antimalaria berdasarkan kategori Gyssens. Hasil disajikan dalam bentuk tabel berupa presentase kerasionalan pemberian antimalaria dan untuk melihat ketepatan penggunaan obat lain yang digunakan pasien malaria yang menggunakan katagori DPR.

\section{HASIL DAN PEMBAHASAN}

Pola penggunaan obat kombinasi $(57,69 \%)$ dan penggunaan obat tunggal $(42,31 \%)$ dengan kombinasi Antimalaria yang banyak digunakan derivat Dehydroartemisin/DHP (Arterakin $®)+$ Primakuin $(44,87 \%)$. Lama rawatan/(LOS) $(33,33 \%)$ dengan lama rawatan 1-2 hari, $(60,25 \%)$ dengan lama rawatan 3-7 hari dan $(6,41 \%)$ dengan lama rawatan 8-14 hari.

Tabel 1. Karakteristik Klinis Pasien Malaria

\begin{tabular}{lcc}
\hline \multicolumn{1}{c}{ Parameter } & Jumlah Pasien & Persentase (\%) \\
\hline Perubahan Diagnosa & & \\
$-\quad$ Tetap & 78 & 77,23 \\
$-\quad$ Berubah & 23 & 22,77 \\
\hline Total & $\mathbf{1 0 1}$ & \\
\hline Komplikasi & & \\
$-\quad$ Tanpa komplikasi & 22 & 28,21 \\
$-\quad$ Komplikasi & 56 & 71,79 \\
\hline Total & $\mathbf{7 8}$ & \\
\hline Tingkat Keparahan * & & 74,36 \\
$-\quad$ Ringan & 58 & 25,64 \\
$-\quad$ Sedang & 20 & \\
\hline Total & $\mathbf{7 8}$ & 42,31 \\
\hline Pola Penggunaan Obat $*$ & & 57,69 \\
$-\quad$ Tunggal & 33 & \\
$-\quad$ Kombinasi & 45 & \\
\hline Total & $\mathbf{7 8}$ & \\
\hline
\end{tabular}

Sumber: Data Rekam Medik Pasien 2014

Hasil analisis regresi logistic menggunakan model persamaan kedua yang memasukkan semua komponen dari variabel independen. Dari tabel Variables in the Equation terlihat nilai pada kolom $\operatorname{Exp(B)~mendekati~satu~yaitu~kelompok~usia~yang~berarti~kelompok~usia~4,314~kali~}$ 
lebih beresiko dan berpengaruh secara signifikan terhadap terjadi perubahan diagnosa dibandingkan dengan jenis kelamin dan pendidikan.

Berdasarkan hubungan pola penggunaan obat terhadap lama rawatan tidak berbeda secara bermakna $\mathrm{p}=0,854$ dengan tingkat kepercayaan (confidence interval) sebesar 95\%. Meskipun tidak berbeda secara bermakna tetapi lama rawatan menggunakan obat kombinasi lebih singkat dengan rata-rata rawatan 3,56 hari dibandingkan menggunakan obat tunggal yang lebih lama dengan rata-rata 3,64 .

Hubungan antara kombinasi obat terhadap lama rawatan tidak berbeda secara bermakna $\mathrm{p}=0,220$. Meskipun tidak berbeda secara bermakna tetapi lama rawatan menggunakan kombinasi derivate Dihydroartemin (Arterakin $\left.{ }^{\circledR}\right)+$ Primaquin lebih singkat dengan rata-rata dirawat 3,50 hari dibandingkan dengan menggunakan kombinasi Chloroquin $\left(\right.$ Malarex $\left.{ }^{\circledR}\right)+$ Sulfadoxin-pyritamine $\left(\right.$ Suldox $\left.{ }^{\circledR}\right)$ dengan rata-rata lama rawatan 3,73 hari.

Hubungan kerasionalan obat terhadap lama rawatan berbeda secara bermakna $\mathrm{p}=0,00$ dari 78 pasien, hanya 43 pasien yang rasional menggunakan obat dengan rata-rata dirawat 3,02 hari lebih singkat dibandingkan dengan penggunaan obat tidak rasional dengan rata-rata dirawat 4,89 hari. Rasionalitas penggunaan antimalaria dikaji menggunakan Metode Gyssens belum melibatkan tim PPRA, alur penilaian dan klasifikasi atau katagori yang digunakan yaitu katagori Van Der Meer dan Gyssens (2001) dimana hasil penilaian penggunaan antimalaria yang sudah tepat atau sesuai (34,26\%) Antimalaria yang sudah efektif sebesar 81,82\% dan Antimalaria yang tidak toksik sebesar $89,26 \%$.

\section{PEMBAHASAN}

Hasil analisis hubungan pola penggunaan obat terhadap komplikasi tidak berbeda secara bermakna $\mathrm{p}=0,712$, ternyata pasien yang mengalami komplikasi lebih banyak menggunakan obat kombinasi dibandingkan obat tunggal hal ini membuktikan bahwa di RSUD Dr. M. Yunus Bengkulu sendiri sudah adanya pedoman terapi malaria yang jelas dan pengendalian resistensi antimlaraia. Tujuan terapi kombinasi ini adalah untuk pengobatan yang lebih baik, mencegah relapas dan mencegah terjadinya resistensi Plasmodium terhadap obat antimalarial (Depkes, 2014) dan penggunaan golongan Artemisisn berbasis terapi kombinasi dapat memperlambat perkembangan resistensi dan mengurangi penularan malaria (White, et al., 1996). Sedangkan 
penggunaan obat tunggal terutama golongan Artermisisn sudah dilaporkan banyak terjadi relaps pada pasien malaria (Tracy, et al.,2001) dikarenakan waktu paruh yang singkat (WHO, 2012; Depkes, 2014) .

Sejalan dengan studi yang telah dilaporkan dibeberapa Negara diantaranya diseluruh Afrika, penggunaan obat tunggal atau monotrapi antimalaria seperti Chloroquin dan Sulfadoxinpyrithenamine dapat meningkatkan resiko morbiditas dan mortalitas 33,1\% (Dodoo, et al., 2009). Dan juga penelitian yang dilakukan oleh Igboeli, et al., (2010) di Nigerian Hospital telah dilaporkan penggunaan obat tunggal Chloroquin dan Sulfadoxin-pyrithenamin $77 \%$ kurang efektif dikarenakan telah resistensi terhadap Plasmodium falsifarum dan sering terjadi relaps (Tracy, 2001). Di Bengkulu sendiri jenis Plasmodium yang paling banyak menginfeksi yaitu Plasmodium falsifarum.

Hasil analisis hubungan pola penggunaan obat terhadap lama rawatan walaupun tidak berbeda secara bermakna $\mathrm{p}=0,854$ ternyata penggunaan obat tunggal lebih lama rawatan di bandingkan dengan penggunaan obat kombinasi, sehingga untuk penggunaan obat kombinasi lebih efektif dibandingkan dengan obat tunggal dilihat dari lama rawatan.

Hasil analisis hubungan penggunaan obat kombinasi terhadap lama rawatan tidak berbeda secara bermakna $\mathrm{p}=0,220$. Obat kombinasi yang digunakan di RSUD Dr. M. Yunus terdapat 2 golongan yaitu kombinasi derivate Dihydroartemisin (Arterakin®)+Primaquin dan Chloroquin (Malarex $\left.{ }^{\circledR}\right)+$ Sulfadoxin-pyritamine(Suldox $\left.®\right)$, ternyata menggunakan derivate Dihydroartemisin (Arterakin $\left.{ }^{\circledR}\right)+$ Primaquin lebih singkat sehingga lebih efektif dibandingkan menggunakan Chloroquin (Malarex $\left.{ }^{\circledR}\right)+$ Sulfadoxin-pyritamine(Suldox®) dilihat dari lama rawatan.

Dari hasil uji statistik yang tidak berbeda secara bermakan baik pada pola penggunaan obat tunggal maupun kombinasi sebenarnya dapat membuktikan bahwa penggunaan Chloroquin $($ Malarex $\AA)+$ Sulfadoxin-pyrimethamine (Suldox $®)$ masi dikatakan efektif untuk pasien malaria berdasarkan lama rawatan yang tidak berbeda secara bermakna dengan penggunaan derivate dehydroartemisin (Arterakin®)+Primaquin tetapi perlu dilakukan penelitian lebih lanjut tentang kejadian relaps pada pasien yang menggunakan obat tunggal dan obat kombinasi Chloroquin $\left(\right.$ Malarex $\left.{ }^{\circledR}\right)$ + Sulfadoxin-pyrimethamine (Suldox $($ ) dikarenakan telah dilaporkan pada penelitian sebelumnya yaitu seorang penderita malaria rata-rata mengalami serangan ulang sebanyak 35-40 kali per 3-4 tahun di propinsi Bengkulu. Sejalan dengan studi yang telah 
dilaporkan sebelumnya di Nigeria penggunaan Cloroquin dan Sulfadoxin-pyrimethamine 77\% kurang efektif untuk pengobatan malaria tanpa komplikasi dikarenakan resistensi Plasmodium falsiparum dan terjadi relaps sebesar 60\% (Tracy JW, 2001). Untuk mengatasi masalah tersebut, antimalaria yang digunakan sebaiknya sesuai dengan yang direkomendasikan oleh pemerintah.

Hasil analisis hubungan kerasionalan terhadap lama rawatan berbeda secara bermakna $\mathrm{p}=0,00$, obat yang tidak rasional lebih lama rawatan dibandingkan dengan yang rasional, berarti untuk penggunaaan obat rasional lebih baik dan lebih efektif serta efisien dibandingkan dengan yang tidak rasional dilihat dari lama rawatan. Penggunaan obat yang rasional dapat ditingkatkan dengan cara melibatkan peran apoteker dalam pengobatan pasien tujuanya untuk mencegah terjadinya resistensi relaps, toksisitas, dan efek samping yang merugikan sehingga waktu perawatan akan menjadi lebih cepat, biaya pengobatan menjadi lebih murah dan dapat menghemat anggaran pengeluaran rumah sakit.

Menurut WHO pengobatan dikatakan rasional yaitu jika penggunaan obat telah sesuai dengan kebutuhan klinis, dosis dan frekuensi pemberian obat yang tepat serta biaya yang rendah dan mudah dijangkau, Untuk mengatasi masalah penggunaan obat yang tidak rasional diperlukan beberapa upaya perbaikan dan intervensi, baik di tingkat provider yaitu peresep (prescriber) dan penyerah obat (dispenser) dan pasien/masyarakat (consumer) hingga sistem kebijakan obat nasional. Adapun efek Jika diagnosis tidak ditegakkan dengan benar, maka pemilihan obat akan terpaksa mengacu pada diagnosis yang keliru akibatnya obat yang diberikan juga tidak akan sesuai dengan indikasi yang seharusnya (WHO, 2011).

\section{KESIMPULAN}

Pola penggunaan obat pada pasien dengan komplikasi dan tingkat keparahaan sedang tidak berbeda dengan pasien tanpa komplikasi dan tingkat keparahan ringan $p>0.1$. Lama rawatan pasien tergantung pada tingkat keparahan penyakit, tingkat keparahan sedang lebih lama rawatanya dibandingkan dengan tingkat keparahaan ringan $\mathrm{p}<0,1$. Pasien yang mendapat terapi rasional akan dirawat lebih singkat dan biaya yang lebih murah dibandingkan terapi yang tidak rasional $\mathrm{p}<0,1$. 


\section{DAFTAR PUSTAKA}

Azwar A. 1981. Pengantar Ilmu Kedokteran Pencegaha. Bagian Ilmu Kesehatan Masyarakat dan Ilmu Kedokteran Pencegahan Fakultas Kedokteran Universitas Indonesia, Jakarta.

Chedi., Abu-aguye, Kwanashie, IA.,\& HO. 2010. Interventional Studies Of Anti-malarial Drug Utilization In Public Health Facilities in Kano, Nigeria. Bayero Journal or Pure and Applied Sciences, 3(1): 49-53.

Departemen Kesehatan Republik Indonesia. 2009. Pedoman Penatalaksanaan Kasus Malaria di Indonesia. Dirjend. PP \& PL., Jakarta.

Departemen Kesehatan Republik Indonesia. 2014. Pedoman Pengendalian Vektor Malaria, Direktorat PPBB, Jakarta.

Dodoo AN., Fogg, C., Asiimwe, A.,Nartey, E.T., Kodua, A., Tenkorang, O., \& Ofori-Adjei, D. 2009. Pattern Of Drug Utilization For Treatment Of Uncomplicated Malaria in Urban Ghana Following National Treatment Policy Change To Artemisin-Combination Therapy, Malaria Journal 2009, 8(2), 1-8. Doi: 10.1186/1475-2875-8-2 dalam http://www.malariajournal.com/content/8/1/2

Ernawati, K., Soesilo, B., Duarsa, A., \& Rifqatussa'adah. 2011. Hubungan Faktor Risiko Individu Dan Lingkungan Rumah Dengan Malaria Di Punduh Pedada Kabupaten Pesawaran Propinsi Lampung Indonesia 2010. Markara Kesehatan, 15(2), 51-57.

Gunawan, S. 2000. Epidemiologi Malaria, dalam: Harijanto, P.N. (ed): Malaria: Epidemiologi, Manifestasi Klinis, Dan Penanganan, EGC, Jakarta.

Harrison, NE., Olufunlayo \& Agomo C.O. 2011. Utilization Of The Current National Antimalarial Treatment Guidelines Among Doctors In Army Hospitals in Lagos, Nigeria, Open Journal Of Preventive Medicine, 2(3), 390-393, dalam http://dx.doi.org/10.4236/ojpm. 2012.23056

Igboeli NU, Ukwe CV, Ekwunife OI. 2010. Increasing Use of Artemisinin-Based Combination Therapy For Treatment Of Malaria Infection In Nigerian Hospitals, Pharmacy Practice (Online) OctDec:8(4):243-249.

Keputusan Menteri Kesehatan RI No. 293/MENKES/SK/IV/2009. tentang Eliminasi Malaria Di Indonesia. Direktorat Jendral P2PL. 2009. Departemen Kesehatan.

Limbachia, DM., Desai, RN., Anand, IS., \& Patel, CN. 2012. Drug Utilization study Of Anti-Malarial Drug In A Tertiary Care Hospital. American Journal Of Pharmtech Reseach, 2 (4)(4). Dalam : http://www.ajptr.com/

Mosanya, ME. 2001. Strategies for implementing roll back malaria: thr role of pharmacist. Nigerian. Journal of Pharmacy, 32: 20-24.

Mubeen, F., Haerdeep, Pandey, DK., \& Jaheer, M. 2012. Drug Utilization Pattern Of Antimalarial Drugs At Tertiary Care Hospital : A Retrospective Study. Int J Med Pharm Sci, 03(05), 1-5.

Peraturan Menteri Kesehatan RI No.374/Menkes/PER/III/2010 Tentang Pengendalian Vektor Tahun 2012. 
Siahaan Lambok. 2008. Gejala dan Tanda Klinis Malaria di Daerah Endemis. Departemen Parasitologi Fakultas Kedokteran Universitas Sumatra Utara, Medan. Majalah Kedokteran Indonesia, Volum: 58, Nomor: 6, Juni 2008.

Susanna D. 2005. Pola Penularan Malaria Di Ekosistem Persawahan, Perbukitan dan Pantai (Studi Di Kabupaten Jepara, Purworejo Dan Kota Batam).

Sutisna P. 2004. Malaria Secara Ringkas, Jakarta, EGC.

Tracy JW, Webster LT. 2001. Malaria In: Hardman JG, Limbird LE, Gilman AG (Ed). Goodman and Gilman's. The Pharmacological Basis Of Therapeutics. 10 edition. McGraw-Hill Companies, Inc Unites States Of America.

Wells. BG., Dipiro, JD., Terry.LS., Cecily. FP. 2009. Pharmacitherapy Handbook, Seventh Edition, The McGraw-Hill Companies, Inc, New York.

White NJ, Olliaro PL. 1996. Strategies For The Prevention Of Malarial Drug Resistance: Rational For Combination Chemotherapy For Malaria. Parasit Today. 1996;12;399-40.

WHO-USAID. 2002. Report on a malaria control project in the menorah hills area central java, municipality of Jogjakarta, Indonesia. Collaborative Project.

World Health Organization. 1995. How to investigate drug use in helath facilities (Selected drug use indicator). Action Program on Essentiol Drug, WHO: Geneva, pp 87.

World Health Organization. 2006. Guildine for The Treatment of Malaria. Switzerland.

World Health Organization. 2011. World Malaria Report 2011, Geneva. 